\title{
A New Phase for the Nexus Network Journal
}

\author{
Kim Williams
}

Published online: 6 March 2014

(C) Kim Williams Books, Turin 2014

\begin{abstract}
Editor-in-Chief Kim Williams opens volume 16 number 1 (Winter 2014) of the Nexus Network Journal by presenting new developments for this journal, including the introduction of Michael J. Ostwald as co-Editor-in-Chief.
\end{abstract}

Volume 16 (2014) of the Nexus Network Journal ushers in a new phase for our publication, which I am pleased to introduce to our readers.

First of all, I am very happy to announce that Michael J. Ostwald of the University of Newcastle is now collaborating with me as Co-Editor-in-Chief of the NNJ. I have been covering this role on my own since the journal's founding in 1999, and welcome not only helping hands and eyes, but a fresh outlook and second perspective on both the journal and the field it serves. When the NNJ was founded the discipline of architecture and mathematics did not even exist as such, and now it is acknowledged and thriving around the globe. Michael began his collaboration with the Nexus conferences and the NNJ in 1998, when he presented a paper at the second Nexus conference, which took place in Mantua, Italy. He also presented papers at Nexus 2006 in Genoa; 2008 in San Diego, and in 2012 in Milan ["Differentiating between Line and Point Maps Using Spatial Experience: Considering Richard Neutra's Lovell House", Nexus Network Journal 15 (2013): 63-81]. He is the author of one of the NNJ papers most frequently cited, even at a distance of 14 years from its original publication ["Under Siege: The Golden Mean in Architecture", Nexus Network Journal 2 (2000): 75-82]. He has been a member of the NNJ editorial board since 2002, first as Book Review Editor and then, from 2004, as a Corresponding Editor, and as co-editor with me of the forthcoming two-volume publication of updated versions of a selection of papers that had previously appeared in past volumes of

K. Williams $(\bowtie)$

Kim Williams Books, Corso Regina Margherita, 72, 10153 Turin, Italy

e-mail:kwb@kimwilliamsbooks.com

Birkhäuser 
the Nexus conference books (Architecture and Mathematics from Antiquity to the Future, due to be published by Birkhäuser in 2014, in time for Nexus 2014 in Ankara, Turkey), he has as broad understanding as possible of architecture and mathematics as a field as well as of the Nexus conferences and the $N N J$ as an endeavor. Thus it is with gratitude and enthusiasm that I begin this new phase of collaboration.

Several new collaborators have joined the Editorial Board of the NNJ for 2014. It is a pleasure to welcome Maria Zack, Marco Giorgio Bevilacqua, Hooman Koliji and Sambit Datta to the board. Meet all the editorial board members on the Nexus Network Journal website at http://www.nexusjournal.com/ eb-intro/eb-intro.html.

Another change that some readers will notice regards the page layout of the journal. The NNJ has been co-published by Kim Williams Books in Turin and Birkhäuser in Basel (now a program of Spring-Basel) since volume 8. To take advantage of the features found in other scientific journals published by Springer, such as citation tracking, online links to references and so forth, we have changed our production process and consequently the layout. We find its appearance to be scientific and modern, crisp and easy to read, and especially effective for online reading and navigation. This is sure to be a benefit for future research.

This first issue of this volume 16 (2014) of the Nexus Network Journal is dedicated to reciprocal structure and guest edited by Alberto Pugnale. This is the latest in a series of special issues dedicated to specific topics. Past issues, for example, have been dedicated to individual architects (Leonardo, NNJ vol. 10, no. 1; Palladio, $N N J$ vol. 10, no. 1), disciplinary fields that involve architecture and mathematics (archaeoastronomy, $N N J$ vol. 15, no. 3; digital fabrication, $N N J$ vol. 14, no. 3; shape grammar, $N N J$ vol. 13, no. 1); geographical regions (Persia, $N N J$ vol. 14, no. 2), and research topics of special interest (the golden section, $N N J$ vol. 4, no. 1; perspective and optics, $N N J$ vol. 5, no. 1). We very much like these special issues, as they allow guest editors to draw on pools of researchers that may not have previously published in our journal and come from different but related fields of inquiry. They also allow groups of papers to reach those readers particularly interested in a given topic, thus fostering research and references. We therefore welcome proposals for special issues.

The group of sixteen papers about reciprocal structures gathered here are introduced by Guest Editor Alberto Pugnale in his Letter from the Guest Editor. They are complemented by two additional works to complete the issue. Ahmed Elkhateeb presents the first of a four-part series in the Didactics column with "Remarks on the Surface Area and Equality Conditions in Regular Forms. Part I: Triangular Prisms". This interesting series examines some mathematical notions regarding form as applied to architecture that might at first glance appear quite basic, but the treatment is novel and quite particular to design, and will benefit many teachers and students alike. The other three parts of this series will appear in forthcoming issues. Michela Rossi re-examines a classic text in her Review of The Theory of Proportion in Architecture by P. H. Scholfield, which was reissued by Cambridge University Press 53 years after its original publication. 
My best wishes to all our readers,

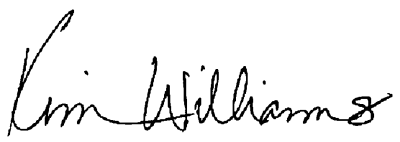

Kim Williams received her degree in Architectural Studies from the University of Texas in Austin, and did her apprenticeship in the offices of Philip Johnson in New York. She became interested in mathematics and architecture while writing Italian Pavements: Patterns in Space (Houston: Anchorage Press, 1998) about the role of decorated pavements in the history of Italian architecture. In 1996 she began the international conference series "Nexus: Relationships Between Architecture and Mathematics," In 1999 she founded the Nexus Network Journal to provide a dedicated venue for scholarly research in architecture and mathematics. In 2000 she founded Kim Williams Books, an independent press for books about architecture and mathematics. Her latest book, co-edited with Michael Ostwald, is the twovolume Architecture and Mathematics from Antiquity to the Future (Birkhäuser, 2014). 